\title{
Chemical Composition and Antimicrobial Properties of Elettaria cardamomum Extract
}

\author{
Faiza MOULAI-HACENE ${ }^{1}$, Mokhtaria Yasmina BOUFADI ${ }^{2,3, *}$, Soumia KEDDARI ${ }^{2}$, Abdelkader HOMRANI'
}

\section{Faiza MOULAI-HACENE',} Mokhtaria Yasmina BOUFADI 2,3,*, Soumia KEDDARI², Abdelkader HOMRANI ${ }^{1}$

\section{'Laboratory of Sciences and Techniques of Animal Production (LSTPA), Faculty of Natural Sciences and Life, Abdelhamid Ibn Badis University, Mostaganem, ALGERIA. 'Laboratory of Beneficial Microorganisms, Functional Food and Health (LMBAFS), \\ Faculty of Natural Sciences and Life, Abdelhamid Ibn Badis University, Mostaganem, ALGERIA. \\ ${ }^{3}$ Laboratory of Pharmaceutical Chemistry, Faculty of Pharmacy, Université Libre de Bruxelles, Brussels, BELGIUM.}

\section{Correspondence}

\section{Mokhtaria Yasmina BOUFADI}

Faculty of Natural Sciences and Life Abdelhamid Ibn Badis University,

Mostaganem.

ALGERIA.

Phone no: +21355836 6319

E-mail: yasmina.boufadi@univ-mosta.dz

History

- Submission Date: 01-05-2020;

- Review completed: 02-07-2020;

- Accepted Date: 08-07-2020.

DOI : 10.5530/pj.2020.12.149

Article Available online

http://www.phcogj.com/v12/i5

Copyright

(c) 2020 Phcogj.Com. This is an openaccess article distributed under the terms of the Creative Commons Attribution 4.0 International license.

\begin{abstract}
Introduction: Cardamom, also known as Elettaria cardamomum, a venerated perennial herb like the "Queen of Spices" belongs to the Zingiberaceae family. She holds various pharmacological activities due to its phytochemicals it contains such as; phenols, tannins, terpenoids, flavonoids, sterols. Methods: The study included the determination of the chemical composition of Elettaria cardamomum ethanolic extract (EEC) by HPLC/UV and evaluated their antimicrobial potential against ten pathogenic reference strains using two complementary techniques: the method of diffusion from solid discs and the determination of minimum inhibitory concentrations (MIC). Results: The results obtained from chemical identification of the EEC showed the presence of polyphenolic acids (rosmarinic acid, caffeic acid, ferulic acid, etc.) and many flavonoids (kaempferol, chrysin, galangin, pinocembrine, quercetin, etc.). The results of the antimicrobial effect showed that the extract reacted positively on almost all the microbial strains tested. The EEC extract significantly inhibited the growth of microbial strains, with a broader antimicrobial spectrum with extensive action with inhibitory zones between 8 and $33 \mathrm{~mm}$ in diameter. Thus, this extract revealed a dose-dependent antimicrobial activity on these microbial strains used. However, the inhibitory potential of the cardamom extract was variable compared to their MIC ranging from 6.25 to $12.5 \mathrm{mg}$ of dry extract $/ \mathrm{mL}$. Therefore, the strains least susceptible to EEC are Bacillus subtilis, Escherichia coli, Aspergillus niger and Candida albicans. Conclusion: This activity is due to the phenolic compounds produced by the EEC extract. This extract can be used for the development of plant medicines against microbial infections and fungal infestations.
\end{abstract}

Key words: Antimicrobial activity, Chemical composition, Elettaria cardamomum, Pathogenic strains.

\section{INTRODUCTION}

Currently, the phenomenon of bacterial resistance is known in all antibiotic families and affects almost all bacterial species. The resistance extends both quantitatively and qualitatively. For more than 20 years, many determinants of resistance have been described with the emergence of increasingly resistant bacteria. ${ }^{1}$ This has generated considerable interest in researching new drugs or preparations from natural sources, including plants. 2,3

The use of plant extracts and compounds of plant origin are valuable sources for traditional medicine in the treatment and prevention of infectious diseases. ${ }^{4}$ Thus, they can become the basis of drug development, a natural model for the development of new drugs. ${ }^{5}$

Similarly, according to the WHO, ${ }^{6}$ more than $80 \%$ of the world's population use medicinal plants to treat several diseases. ${ }^{7}$ Indeed, natural substances of plant origin are endowed with several biological activities such as antioxidant, anti-inflammatory, anticancer, antimicrobial activity.

In addition, many herbs used by Ayurvedic practitioners have promising results and may be appropriate for larger randomized trials. It is assumed that the broad-spectrum efficacy of these spices can provide an appropriate basis for new antimicrobial therapies. ${ }^{8}$ The main groups of antimicrobial phytocompounds include alkaloids, anthraquinones, cardiac glycosides, saponins, tannins and polyphenols. ${ }^{9}$

Some of these herbs are those of the genus:

Elettaria; herbaceous perennial, Elettaria cardamomum (EC), revered as the "queen of spices", belongs to the ginger family, Zingiberaceae. ${ }^{10,11}$ The seed contains phytochemical compounds such as phenols, starch, tannins, terpinoids, flavonoids, proteins and sterols. ${ }^{12}$

It has been used to treat infections of the gums, teeth and throat and to treat pulmonary congestion, tuberculosis, high blood pressure, heart disease and digestive disorders. ${ }^{13}$ Anti-inflammatory, anti-proliferative, pro-apoptotic ${ }^{14}$ and antioxidant activities have been recognized as mechanisms underlying the anticancer properties of cardamom. ${ }^{13}$

Recently, it has been found that cardamom extract acts as a powerful modulator of macrophages ${ }^{15}$ and as a protective factor against uranium risks. ${ }^{16}$ Elgayyar and Sekine ${ }^{17-18}$ reported that cardamom extract has well-recognized antimicrobial and antifungal properties. Analgesic, antidepressant, anticonvulsive and antispasmodic activities have been attributed to this plant. ${ }^{19,20}$

Cite this article: Moulai-Hacene F, Boufadi MY, Keddari S, Homrani A. Chemical Composition and Antimicrobial Properties of Elettaria cardamomum Extract. Pharmacogn J. 2020;12(5):105863. 
This study aims to identify the chemical composition of the extract of Elettaria cardamomum, to characterize the mode of action of extract with antimicrobial activity and to determine the minimum inhibitory concentration of this extract towards pathogenic microorganisms.

\section{MATERIALS AND METHODS}

\section{Drugs and reagents}

The TFA, EtOH, acetonitrile, formic acid, were obtained from SigmaAldrich (St Louis, MO, USA). The Mueller Hinton agar was also purchased from Merck.

\section{Extraction of Elettaria cardamomum}

The fruits of E.cardamomum, locally called "Hab el Hal" were bought dry from an herbalist in the city of Mostaganem in northwest Algeria. They were, identified and authenticated by the botanist Pr Larid Mohamed in Laboratory of Biodiversity and Water and Soil Conservation from the Mostaganem University. They were crushed with a mortar until a fine powder was obtained, then placed in hermetically sealed jars and stored dry (room temperature) and protected from humidity.

Extraction of the plant material was carried out according to the protocol of Masoumi-Ardakani ${ }^{21}$, which consists of placing $200 \mathrm{~g}$ of powdered plant material in contact with $1000 \mathrm{~mL}$ of absolute ethanol. The preparation was left to macerate at room temperature for 72 hours in a dark place. After filtration with a Whatman No. 1 paper, the recovered ethanolic extract was concentrated using rotavapor to evaporate the ethanol. The ethanolic extract of E. cardamomum (EEC) was recovered in a dark glass vial and stored at $4{ }^{\circ} \mathrm{C}$.

\section{HPLC/UV analysis of phenolic compounds from $E$.} Cardamomum extract

The chromatographic analysis of ethanolic extract of Elettaria cardamomum (EEC) was performed by high performance liquid chromatography (Agilent 1100). Separation was carried out on an Agilent 120EC poroshell column (100 $\mathrm{mm} \times 2.1 \mathrm{~mm}, 2.7 \mu \mathrm{m})$ using mobile phases: water/TFA/formic acid (99: 0.25: 0.75) (A) and acetonitrile (B). Elution was carried out at a flow rate of $0.6 \mathrm{~mL} \cdot \mathrm{min}^{-1}$ with an aliquot of $10 \mu \mathrm{L}$ and at a temperature of $55^{\circ} \mathrm{C}$, using a gradient method as follows (t.min ${ }^{-1}, \%$ B): $(0,0),(1,10),(2,12.5),(3,15),(9$, $80),(10,100),(11,100),(14,0)$ with post $5 \mathrm{~min}$. Chromatograms were recorded at 270 and $320 \mathrm{~nm}$.

The sample was prepared by diluting EEC with methanol at 1:100 (v/v). Cardamom components were identified by comparing their retention times and UV spectra with different phenolic standards (transcinnamic acid, gallic acid, benzoic acid, ferulic acid, m-coumaric acid, caffeic acid, rosmarinic acid and ellagic acid), flavonoids (catechin, hesperidin, thymol, galangin, tectochrysin, pinocembrin, acetine, rutin, chrysin, apigenin, kaempferol and quercetin) and other compounds (ascorbic acid, menthol). The standards were dissolved in methanol to give stock solutions at $1 \mathrm{mg} \cdot \mathrm{mL}^{-1}$. The quantification of the constituents was determined using standard curves expressed in mg per $1 \mathrm{~g}$ of crude cardamom.

\section{Antimicrobial potency}

\section{Microbial strains and culture preparations}

Ten microbial strains were selected and used in this study given their degree of pathogenicity and virulence. Four gram-positive bacterial strains (Bacillus cereus ATCC 10876, Bacillus subtilis ATCC 6633, Staphylococcus aureus ATCC 33862 and Carnobacterium maltoaromaticum 20722) and four gram-negative bacterial strains (Pseudomonas aeruginosa ATCC 27853, Escherichia coli ATCC 25922,
Enterobacter sp. and Schigella ssp.), plus two fungal strains (Candida albicans ATCC 10231 and Aspergillus niger ATCC 106404).

The strains were maintained on Mueller Hinton agar tilts. Antimicrobial activity was evaluated in vitro by two methods; the disc diffusion method for determination of inhibition zone diameters and the dilution series method for determination of minimum inhibitory concentrations (MIC).

\section{Disc diffusion methods}

Petri dishes containing Mueller Hinton agar were aseptically inoculated with $100 \mu \mathrm{L}$ of microbial suspension adjusted to $10^{8} \mathrm{CFU} \cdot \mathrm{mL}^{-1}$ turbidity. After a 15 min rest, filter discs (CT0998B, Oxoid, France) containing different concentrations of E. cardamomum extract (12.5, 25, 50 and $\left.100 \mu \mathrm{g} . \mathrm{mL}^{-1}\right)$ were placed on the agar of each Petri plate. The plates were incubated at $37^{\circ} \mathrm{C}$ for 24 hours in aerobic conditions. After $24 \mathrm{~h}$ incubation, the diameters of the inhibition zones were measured using a ruler (Andrews, 2001).

\section{Determination of Minimum Inhibitory Concentration (MIC)}

The Minimum Inhibitory Concentration (MIC) of cardamom extract (EEC) was determined by the liquid-media dilution technique coupled with solid-media spreading as described by Boufadi. ${ }^{22}$ In a test tube, variable EEC concentrates were added, so that the concentration gradient extracts follow a progression geometry of 2 and 0 to $30 \mathrm{mg} /$ $\mathrm{mL}$.

Each tube in one of the series is then inoculated with $1 \mathrm{ml}$ of an inoculum of $10^{8} \mathrm{CFU} / \mathrm{mL}$. Then, all the tubes were incubated in an oven at $37^{\circ} \mathrm{C}$ for $24 \mathrm{~h}$. One millilitre of the contents of each tube was then inoculated in a solid medium. The lowest concentration that completely inhibits the test germ is considered the MIC.

\section{Statistical analysis}

SigmaStat software (SPSS, 3.0, SPSS, Inc., Chicago, IL) was used for the statistical analysis. The data were presented as mean \pm standard deviation and were evaluated by a one-way ANOVA with Dunnett's post-hoc test. The ranked-based ANOVA analysis with Dunn's posthoc test was used where appropriate.

\section{RESULTS}

\section{Chemical composition of EEC extract}

Chromatographic analysis at 270 and $320 \mathrm{~nm}$ of the ethanolic extract of Elettaria cardamomum (EEC) (Figure 1A and B) allowed to identify and quantify the phenolic compounds (Table 1). Comparison of EEC extract retention times with those of different standards revealed the presence of 23 phenolic compounds.

Catechin, luteolin and myricetin were detected as the major flavonoids of EEC extract, with a content of $1.78,1.41$ and $1.25 \mathrm{mg}^{-\mathrm{g}^{-1}}$ EEC, respectively. In addition, the highest phenolic acid content was that of gallic acid (2.83 mg.g ${ }^{-1}$ EEC). Ellagic acid and syringic acid were found at low concentrations.

\section{Antimicrobial activity}

Table 2 shows the results of the antimicrobial activity of EEC extract. The extract reacted positively to virtually all microbial strains tested. Wide variations in the diameters of the inhibition zones obtained ranging from 0.33 to $33.67 \mathrm{~mm}$ were observed.

It can be noted that the diameters of EEC extract inhibition zones corresponding to concentrations 100 and $50 \mu \mathrm{g} \cdot \mathrm{mL}^{-1}$ are higher than those observed with lower concentrations; 25 and $12.5 \mu \mathrm{g} \cdot \mathrm{mL}^{-1}$ except for diameter of Aspergillus niger. Therefore, the EEC extract inhibitory activity seems to be dose-dependent. 


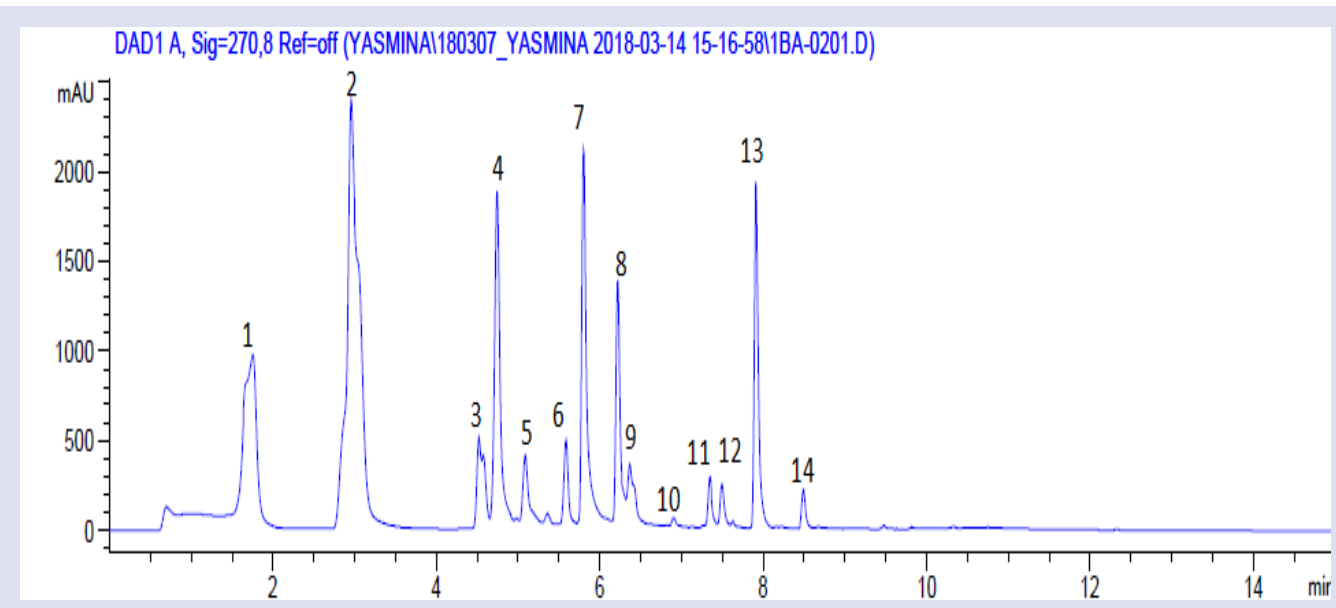

DAD1 B, Sig=320,8 Ref=off (YASMINA1180307_YASMINA 2018-03-14 15-16-5811BA-0201.D)

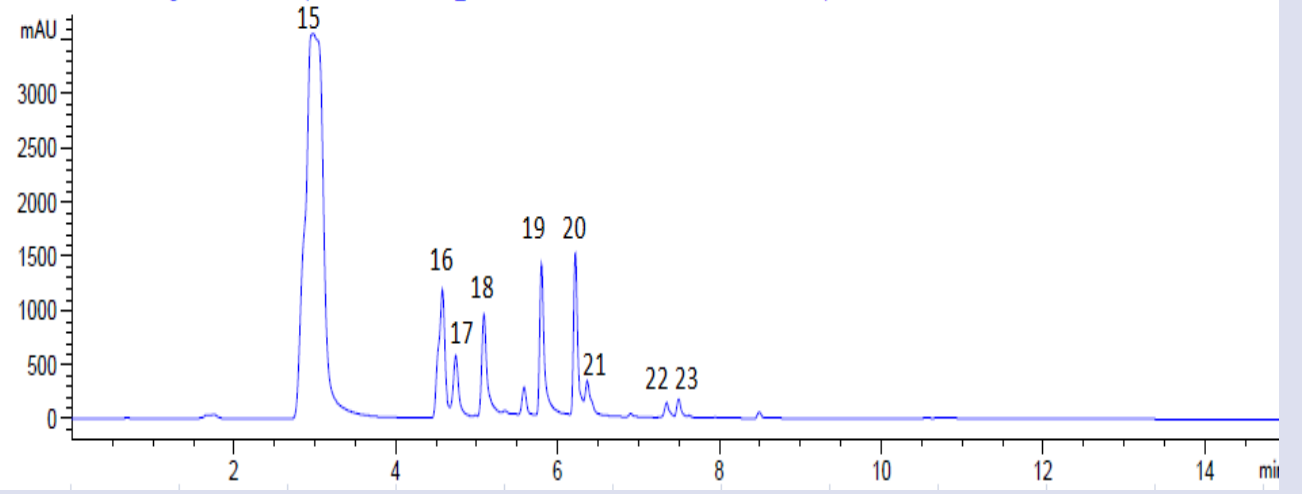

Figure 1: Chromatograms by HPLC/UV analysis of EEC at a wavelength of 270 (A) and $320 \mathrm{~nm}$ (B): 1. Galangin; 2. Catchin; 3. bis quercetin méthyl; 4. quercetin; 5. pinocembrin; 6. apigenin; 7. luteolin ; 8. kaempferol; 9. menthol; 10. acacetin; 11. chrysin; 12. vanillin; 13. myricetin; 14. Thymol ; 15. Gallic acid; 16. Rosmarinic acid; 17.ascorbic acid; 18 Cafeic acid; 19. Ferulic acid; 20. Trans-cinnamic; 21. Tannic acid; 22. Ellagic acid 23. Syringic acid.

Table 1: Chemical composition of ethanolic extract of Elettaria cardamomum (EEC) by HPLC/UV.

\begin{tabular}{cccc}
\hline Peak number & Compounds & Amount $\left(\mathrm{mg} \mathrm{g}^{-1} \mathrm{EEC}\right)$ & Retention time $(\mathrm{min})$ \\
\hline 1 & Galangin & 0,52 & 1,75 \\
2 & Catchin & 1,78 & 2,95 \\
3 & Bis quercetin methyl & 0,32 & 4,57 \\
4 & Quercetin & 1,12 & 4,74 \\
5 & pinocembrine & 0,22 & 5,08 \\
6 & Apigenin & 0,31 & 5,58 \\
7 & luteolin & 1,41 & 5,8 \\
8 & kaempferol & 0,79 & 6,21 \\
9 & Menthol & 0,24 & 6,37 \\
10 & Acacetin & 0,17 & 6,9 \\
11 & Chrysin & 0,21 & 7,34 \\
12 & Vanillin & 0,15 & 7,49 \\
13 & Myricetin & 1,25 & 7,91 \\
14 & Thymol & 0,12 & 8,49 \\
15 & Gallic acid & 2,83 & 2,97 \\
16 & Rosmarinic acid & 0,58 & 4,57 \\
17 & Ascorbic acid & 0,22 & 4,74 \\
18 & Cafeic acid & 0,32 & 5,09 \\
19 & Ferulic acid & 0,80 & 5,8 \\
20 & Trans-cinnamic & Tannic acid & 6,21 \\
21 & Ellagic acid & 0,13 & 6,39 \\
22 & Syringic acid & 0,10 & 7,34 \\
23 & & 7,49 \\
\hline
\end{tabular}


It can also be noted that the EEC extract showed varying degrees of antimicrobial activity against all microbial strains tested. EEC extract showed significant activity $(\mathrm{P}<0.05)$ against Pseudomonas aeruginosa with an inhibition zone diameter of $(31 \mathrm{~mm})$ at a concentration of 50 $\mu \mathrm{g} \cdot \mathrm{mL}^{-1}$.

\section{Minimum inhibitory concentration (MIC)}

Microbial growth is indicated by the presence of a white pellet forming at the bottom of the well. Table 3 shows the MIC of the pathogenic strains. Although antimicrobial susceptibility of various strains varied, cardamom extract was highly effective in inhibiting the growth of all tested strains of most pathogens, with MIC ranging from 6.25 to 12.50 $\mathrm{mg} \cdot \mathrm{mL}^{-1}$.

Bacillus cereus, Carnobacterium maltoaromaticum and Enterobacter $s p$. were the most sensitive pathogens that survived to the lowest concentration (6.25 mg. $\left.\mathrm{mL}^{-1}\right)$ of EEC extract. The inhibition zone produced by EEC against E. coli and Candida albicans ranged from $14.33 \mathrm{~mm}$ to $19.67 \mathrm{~mm}$, respectively.

EEC extract has an inhibitory effect on almost all microbial strains tested. The magnitude of this effect varies between microbial species and different concentrations of EEC. The results show that cardamom has a broad spectrum of action against Gram-positive and Gram-negative bacteria. In addition, EEC expresses an antifungal action against yeast at all concentrations, whereas EEC partially inhibited mould at low concentrations.

\section{DISCUSSION}

Some authors, Elguindy ${ }^{23}$ reported the presence of polyphenolic compounds in the cardamom extract analyzed by HPLC/UV, such as gallic acid, tannic acid, caffeic acid and 4.5-dicaffeoyl quinic acid. In addition, Rahman ${ }^{24}$ noted that the ethanolic extract of cardamom consists of: epicatechin, vanillin, $p$-coumaric acid, trans-ferulic acid and ellagic acid.
Previous work by Hong and Beltran-Ramirez ${ }^{25-26}$ showed the presence of several phenolic components in cardamom seed such as gallic acid, caffeic acid and 4,5-dicaffeoyl quinic acid.

In addition, Kikuzaki and Jessie ${ }^{27-28}$ reported that 1,8-cein, alphaterpineol, Protocatechualdehyde and protocatechic acid present in cardamom seeds show antioxidant activity and have one of the potential health benefits by inhibiting lipid peroxidation. Phytochemical analysis of the aqueous extract of E. cardamomum fruit shows the presence of alkaloids, flavonoids, tannins, terpenoids, reducing sugars, steroids and phenols. ${ }^{29}$

The results of this study are in agreement with the work of MasoumiArdakania $^{21}$, who showed that the methanolic extract of cardamum seeds contains high concentrations of kaempferol, rutin and quercetin.

The same results were confirmed by El Malti and Rajan. ${ }^{30-31}$ The authors reported that the differences observed in the inhibition zone may be due to the different sensitivity of different bacteria to gold nanoparticles (colloids) synthesized by the aqueous extract of Elettaria cardamomum seeds. In addition, Mahady ${ }^{32}$ showed that E. cardamomum seeds have antibacterial activity against Gram-negative bacteria.

In another study, the antibacterial effect of various Elettaria cardamomum fruit extracts was studied on oral bacteria. It was shown that the most significant effect was on S. aureus and that its ethanol and acetone extracts were a potential antibacterial source. ${ }^{33}$

The results of the present study are in agreement with those of Arora and Kaur $^{34}$, who reported that the aqueous extract of E. cardamomum was effective against several pathogenic bacteria in inhibition zones ranging from 15 to $28 \mathrm{~mm}$. Whereas, Nanasombat and Lohasuthawe ${ }^{35}$ found that the ethanolic extract of cardamom seed showed an inhibition zone between 7 to $12 \mathrm{~mm}$ on all strains tested. However, their results were in contrast to the study by Ahmad ${ }^{36}$ who found no antibacterial activity using the aqueous extract; this was due to either the extraction method or strain differences.

Table 2: Diameters of the inhibitions of pathogens strains cultured in the presence of four concentrations $(12.5,25,50$ and $100 \mu \mathrm{g}$ $\mathrm{mL}^{-1}$ ) of ethanolic extract of Elettaria cardamomum.

\begin{tabular}{lcccc}
\hline \multirow{2}{*}{ Microbial strains } & \multicolumn{4}{c}{ Concentrations of ethanolic extract of Elettaria cardamomum $\left(\mu \mathrm{mL}^{-1}\right)$} \\
\cline { 2 - 5 } & 12.5 & 25 & 50 & 100 \\
\hline Staphylococcus aureus ATCC 27853 & $10.67 \pm 1.15$ & $12.67 \pm 1.53$ & $21.67 \pm 1.53$ & $23.33 \pm 0.58$ \\
Bacillus cereus ATCC 10876 & $10.67 \pm 1.15$ & $14.67 \pm 0.58$ & $31.67 \pm 1.53$ & $32.33 \pm 1.15$ \\
Bacillus subtilis ATCC 6633 & $10.00 \pm 0.00$ & $21.00 \pm 1.73$ & $15.00 \pm 0.00$ & $12.67 \pm 1.53$ \\
Carnobacterium maltoaromaticum (DMS) 20722 & $21.33 \pm 1.15$ & $22.67 \pm 0.58$ & $25.33 \pm 1.53$ & $17.33 \pm 0.58$ \\
Shigella sonnei CETC 584 & $08.67 \pm 1.15$ & $09.00 \pm 1.00$ & $17.33 \pm 1.53$ & $14.33 \pm 1.15$ \\
Pseudomonas aeruginosa ATCC 27853 & $18.67 \pm 0.58$ & $21.67 \pm 1.53$ & $31.33 \pm 0.58$ & $33.67 \pm 1.15$ \\
Escherichia coli ATCC 25922 & $0.33 \pm 0.58$ & $14.33 \pm 1.15$ & $17.67 \pm 1.15$ & $15.33 \pm 0.58$ \\
Enterobacter sp & $28.33 \pm 0.58$ & $29.33 \pm 1.53$ & $32.33 \pm 1.53$ & $26.67 \pm 1.53$ \\
Aspergillus niger & $21.67 \pm 1.15$ & $26.67 \pm 1.53$ & $0.33 \pm 0.58$ & $0.00 \pm 0.00$ \\
Candida albicans & $14.33 \pm 0.58$ & $19.67 \pm 1.15$ & $23.33 \pm 0.58$ & $26.67 \pm 1.53$ \\
\hline
\end{tabular}

Table 3: Minimum inhibitory concentration (MIC) in mg of ethanolic extract of Elettaria cardamomum ( $\mathrm{mg} \mathrm{mL}^{-1}$ ) of pathogenic strains.

\begin{tabular}{cc}
\hline Microbial strains & Minimum inhibitory concentrations (CMI) in EEC mg mL \\
\hline Staphylococcus aureus ATCC 27853 & $8.33 \pm 1.61$ \\
Bacillus cereus ATCC 10876 & $6.25 \pm 0.83$ \\
Bacillus subtilis ATCC 6633 & $12.50 \pm 1.22$ \\
Carnobacterium maltoaromaticum (DMS) 20722 & $6.25 \pm 0.09$ \\
Shigella sonnei CETC 584 & $12.50 \pm 1.89$ \\
Pseudomonas aeruginosa ATCC 27853 & $10.42 \pm 2.61$ \\
Escherichia coli ATCC 25922 & $12.50 \pm 2.80$ \\
Enterobacter sp & $6.25 \pm 0.62$ \\
Aspergillus niger & $12.50 \pm 3.28$ \\
Candida albicans & $12.50 \pm 3.28$ \\
\hline
\end{tabular}


Furthermore, Goze ${ }^{37}$ supported this hypothesis by demonstrating that antibacterial extracts could be due to the presence of different compounds in the extracts, which are also influenced by factors such as geographical location, temperature, plant growth phase, harvest period, plant, soil factor, and plant-related genetic and environmental factors.

The results obtained in this study are in agreement with those of El Malti $^{30}$, who showed that the MIC of the cardamom extract ranged from 9.4 to $18.75 \mathrm{mg} \cdot \mathrm{mL}^{-1}$ for all strains tested, with the exception of E. coli, Bacillus cereus and Enterobacter cloacae which were highly sensitive to the extract ( $\mathrm{MIC}<2.34 \mathrm{mg} \cdot \mathrm{mL}^{-1}$ ).

The antibacterial effect of the EEC extract sample can be attributed to their phenolic compounds. The presence of these compounds can increase permeability and eliminate cytoplasmic content by attacking cell membrane phospholipids. In addition, these compounds can affect the enzymes of the bacterial cell walls. ${ }^{38,39}$

\section{CONCLUSION}

This study was taken to identity the chemical composition and antimicrobial potential of Elettaria cardamomum ethanolic extract (EEC). The antimicrobial effect of the EEC extract was studied on ten pathogenic reference strains.HPLC / UV analysis identified and quantified nine phenolic acids and fourteen flavonoids from cardamom extract (EEC). The EEC extract showed strong antimicrobial activity against all of the microbial strains tested. Its inhibitory effect is spectacular, and is due to its richness in phenolic compounds.

All of these results constitute a scientific justification for the use of this spice in traditional pharmacopoeia in the treatment of infectious diseases and confirms once again the relevance of traditional remedies.

\section{ACKNOWLEDGMENTS}

We want to thank Abdelhamid Ibn Badis (Algeria) University and University ULB, CPO Laboratory (Belgium).

\section{FINANCIAL SUPPORT}

There has been no significant financial support for this work that could have influenced its outcome.

\section{CONFLICTS OF INTEREST}

We wish to confirm that there are no known conflicts of interest associated with this publication

\section{DECLARATION OF COMPETING INTERESTS}

None.

\section{REFERENCES}

1. Alekshun MN, Levy SB. Molecular mechanisms of antibacterial multidrug resistance. Cell. 2007;128(6):1037-50

2. Aqil F, Ahmad I, Owais M. In: Modern Phytomedicine: Turning Medicinal plants into drugs. Germany: Wiley-VCH, p. 59-79; 2006.

3. Cowan MM. Plant products as antimicrobial agents. Clin Micro Biol Rev. 1999;12(4):564-82.

4. Al-Bayati AF, Khudir DS. In vitro activité antimicrobienne de salvadora persica L. Thesis, College of Education, Mossoul University, Irak, 2007.

5. Goyal P, Khanna A, Chauhan A, Chauhan G, Kaushik P. In vitro evaluation of crude extracts of Catharanthus roseus for potential antibacterial activity. Int J Gr Phar. 2008;2(3):190-5.

6. World Health Organization (WHO), Report on the global tobacco epidemic, the MPOWER package, Geneva; 2008. http://www.who.int/tobacco/mpower_ report_full_2008. (Accessed on 27 April 2011).

7. Pierangeli G, Vital G, Windell Revera L. Antimicrobial activity and cytotoxicity of Chromolaena odorata (L. f.) King and Robinson and Uncaria perrottetii (A. Rich) Merr, extracts. J Med Plants Res. 2009;3(7):511-8.

8. Kaushik P. Haridra (Turmeric): Antibacterial Potentials, Chowkhamba Sanskrit Series office, K 37/99, Gopal Mandir Lane, Varanasi, Coloured PI 16, p. 1-123; 2003.
9. Tepe B, Daferera D, Sokmen M, Polissiou M, Sokmen A. In vitro antimicrobia and antioxidant activities of the essential oils and various extracts of Thymus eigii. J Agric Food Chem. 2004;52(5):1132-7.

10. Amma KPAP, Rani MP, Sasidharan I, Nisha VNP. Chemical composition, flavonoid-phenolic contents and radical scavenging activity of four major varieties of cardamom. Int J Biol Med Res. 2010;1(3):20-4.

11. Savan EK, Kucukbay FZ. Essential Oil Composition of Elettaria cardamomum Maton, J. J. Appl Biol. Sci. 2013;7(3):42-5.

12. Sharma S, Sharma J, Kaur G. Therapeutic uses of Elettaria cardomum. Int $J$ Drug Formul Res. 2011;2(6):102-8.

13. Das I, Acharya A, Berry DL, Sen S, Williams E, Permaul E, et al. Antioxidative effects of the spice cardamom against non-melanoma skin cancer by modulating nuclear factor erythroid-2-related factor 2 and NF-KB signalling pathways. British Journal of Nutrition. 2012;108(6):984-97.

14. Sengupta A, Ghosh S, Bhattacharjee S. Dietary cardamom inhibits the formation of azoxymethane-induced aberrant crypt foci in mice and reduces COX-2 and iNOS expression in the colon. Asian Pac J Cancer Prev. 2005;6(2):118-22.

15. Vaidya A, Rathod M. An in vitro study of the immunomodulatory effects of Piper nigrum (black pepper) and Elettaria cardamomum (cardamom) extracts using a murine macrophage cell line AIJRFANS. 2014;8(1):18-27.

16. Abdelkader SM, Bauomi AA, Abdel-Rahman M, Mohammaden T, Rezk MM Antioxidant potentials of (Elletaria cardamomum) cardamom against Uranium hazarda. Inter J of Basic and Life Sci. 2015;3(4):64-181.

17. Elgayyar M, Draughon FA, Golden DA, Mount JR. Antimicrobial activity of essential oils from plants against selected pathogenic and saprophytic microorganisms. J of food protection®. 2001;64(7):1019-24.

18. Sekine T, Sugano, M, Majid A, Fujii Y. Antifungal effects of volatile compounds from black zira (Buniumpersicum) and other spices and herbs. Journal of Chemical Ecology. 2007;33(11):2123-32.

19. Al-Zuhair H, El-Sayeh B, Ameen HA, Al-Shoora H. Pharmacological studies of cardamom oil in animals. Pharmacol Res. 1996;34(1):79-82.

20. Baker DG, Nievergelt CM, O'Connor DT. Biomarkers of PTSD: neuropeptides and immune signaling. Neuropharmacology. 2012;62(2):663-73.

21. Masoumi-Ardakani Y, Mahmoudvand H, Mirzaei A, Esmaeilpour K, Ghazvin $\mathrm{H}$, Khalifeh $\mathrm{S}$, et al. The effect of Elettaria cardamomum extract on anxietylike behavior in a rat model of post-traumatic stress disorder. Biomedicine \& Pharmacotherapy. 2017;87:489-95.

22. Boufadi YM, Soubhye J, egrave N, Van Antwerpen J, Ve P, Riazi A. Antimicrobial effects of six Algerian propolis extracts. Int J Food SciTechnol. 2016;51(12):261320.

23. Elguindy MN, Yacout AG, El Azab FE, Maghraby KH. Chemoprotective Effect of Elettaria Cardamomum against Chemically induced Hepatocellular Carcinoma in Rats by Inhibiting NF-kB, Oxidative Stress, and Activity of Ornithine Decarboxylase. South Afr J Bot. 2016;105(26):251-8.

24. Rahman M, Alam MN, Ulla A, Sumi FA, Subhan N, Khan T, et al. Cardamom powder supplementation prevents obesity, improves glucose intolerance, inflammation and oxidative stress in liver of high carbohydrate high fat diet induced obese rats. Lipids Health Disease. 2017;16(1):151.

25. Hong S, Joo T, Jhoo JW. Antioxidant and Anti-inflammatory Activities of 3,5Dicaffeoylquinic Acid Isolated from Ligularia fischeri Leaves. Food Sci and Biotechnol. 2015;24(1):257-63.

26. Beltran-Ramirez O, Aleman-Lazarini L, Salcido-Neyoy M, Hernandez-Garcia $\mathrm{S}$, Fattel- Fazenda S, Arce-Popoca E, et al. Evidence that the anticarcinogenic effect of caffeic acid phenethyl ester in the resistant hepatocyte model involves modifications of cytochrome P450. Toxicol Sci. 2008;104(1):100-6.

27. Kikuzaki H, Kawai Y, Nakatani N. Diphenyl-2-picrylhydrazyl radical scavenging active compounds from greater cardamom (Amomum subulatum Roxb). J Nutr Sci Vitaminol. 2001;47(2):167-71.

28. Jessie SW, Krishnakantha TP. Inhibition of human platelet aggregation and membrane lipid peroxidation by food spice, saffron. Mol Cell Biochem. 2005;278(1):59-63.

29. Prabha M, Anusha TS. Esterase's properties in commonly used Indian spices for Alzheimer's disease model. J of Bioch Tech. 2015;6(1):875-82.

30. El Malti J, Mountassif D, Amarouch H. Antimicrobial activity of Elettaria cardamomum: Toxicity, biochemical and histological studies. Food Chemistry. 2007;104(4):1560-8.

31. Rajan A, Rajan AR, Philip D. Elettaria cardamomum seed mediated rapid synthesis of gold nanoparticles and its biological activities. OpenNano. 2017;2:1-8.

32. Mahady PS, Stoia HF Fabricant DB, Chadwick LR. In vitro susceptibility of Helicobacter pylori to botanical extracts used traditionally for the treatment of gastrointestinal disorders. Phytotherapy Research. 2005;19(11):988-91.

33. Aneja K, Joshi R. Antimicrobial activity of Amomum subulatum and Elettaria cardamomum against dental caries causing microorganisms. Ethnobot Leaflets. 2009;13(7):840-9.

34. Arora DS, Kaur GJ. Antibacterial activity of some Indian medicinal plants. J Nat Med. 2007:61(3):313-7. 
35. Nanasombat S, Lohasupthawee P. Antibacterial activity of crude ethanolic extracts and essential oils of spices against Salmonella and other enterobacteria. KMITL Sci Tech J. 2005;5(3):527-38.

36. Ahmad I, Mahmood Z, Mohammad F. Screening of some Indian medicinal plants for their antimicrobial properties. J Ethnopharmacol. 1998;62(2):183-93.

37. Goze I, Alim A, Tepe AS, Sokmen M, Sevgi K, Tepe B. Screening of the antioxidant activity of essential oil and various extracts of Origanum rotundifolium Boiss from Turkey. J Med Plants Res. 2009:3(4):246-54.
38. Wu J, Chen S, Ge S, Miao J, Li J Z Zhang O. Preparation, properties and antioxidant activity of an active film from silver carp (Hypophthalmichthys molitrix) skin gelatin incorporated with green tea extract. Food Hydrocolloids. 2013;32(1):42-51.

39. Wu J, Ge S, Liu H, Wang S, Chen S, Wans J, et al. Properties and antimicrobia activity of silver carp (Hypophthalmichthys molitrix) skin gelatin chitosan films incorporated with oregano essential oil for fish preservation. Food Pack and Shelf Life. 2014;2(1):7-16

\section{GRAPHICAL ABSTRACT}

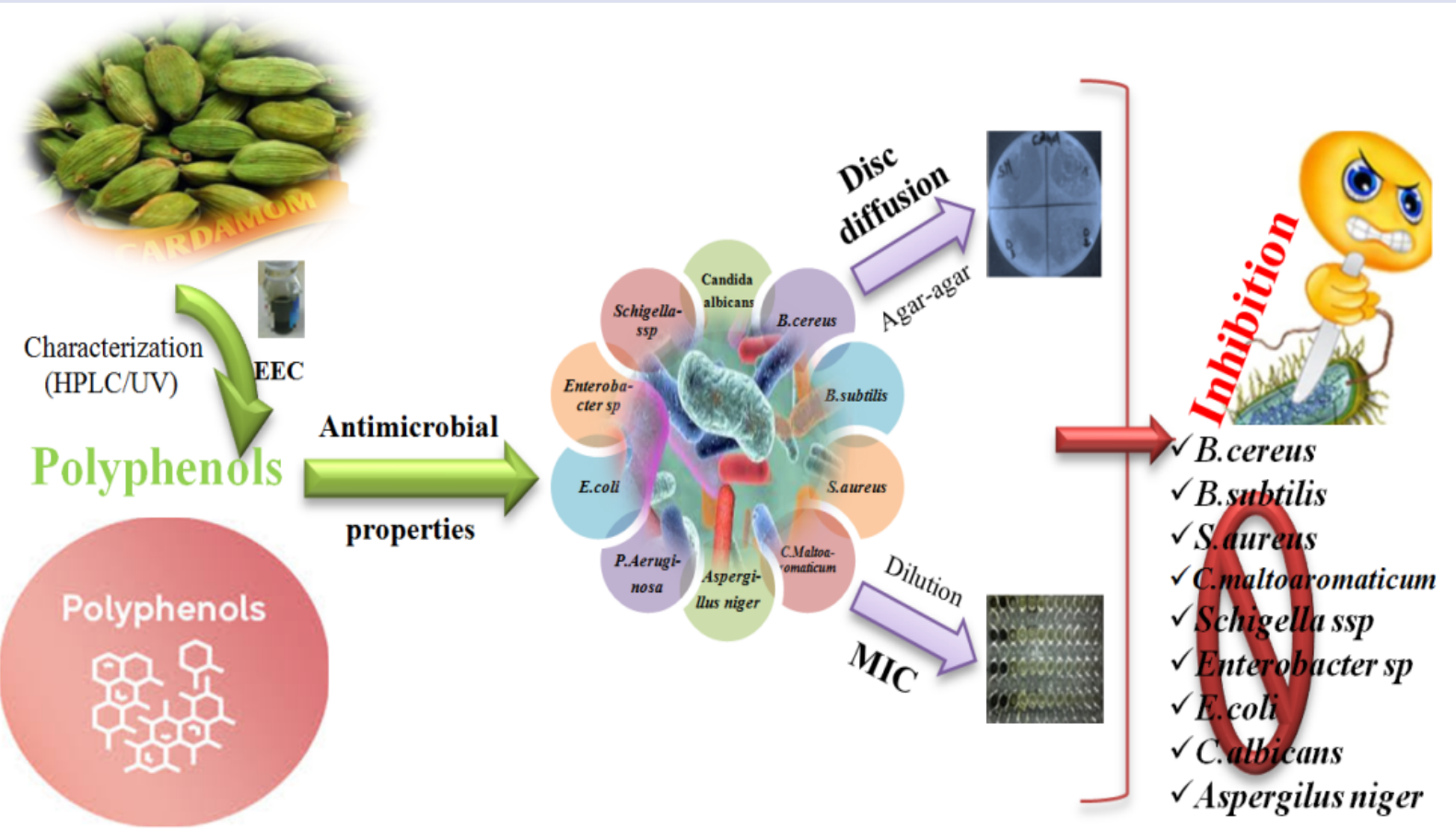

\section{ABOUT AUTHORS}

\section{Dr Mokhtaria Yasmina BOUFADI}

Dr Mokhtaria Yasmina BOUFADI, head of the research team 'Nutraceutiques', at the Laboratory of Beneficial Microorganisms, Functional Foods and Health LMBAFS (University of Mostaganem, Algeria), born on June 20th, 1982, in Saida (Algeria). A doctorate in Human Nutrition in 2014 from the Abdelhamid Ibn Badis Mostaganem University (Algeria). In 2009, Dr Boufadi joined the Abdelhamid Ibn Badis University as well as a research-teacher, she joined the administration as well as head of Research-Training at the Ministry of Higher Education and Scientific Research (MESRS, Algeria).

His research team has developed research on natural substances and their applications in many consumer products.

Cite this article: Moulai-Hacene F, Boufadi MY, Keddari S, Homrani A. Chemical Composition and Antimicrobial Properties of Elettaria cardamomum Extract. Pharmacogn J. 2020;12(5):1058-63. 